\title{
The Effect of Collaboration Network on Inventors' Job Match, Productivity and Tenure.*
}

\author{
Ryo Nakajima ${ }^{\dagger}$ \\ Yokohama National University \\ Ryuichi Tamura ${ }^{\ddagger}$ \\ University of Tsukuba \\ Nobuyuki Hanaki ${ }^{\S}$ \\ GREQAM, Université de la Méditerannée, University of Tsukuba
}

November 22, 2009

\begin{abstract}
It has been argued in the economic literature that job search through informal job networks improves the employer-employee match quality. This paper argues that inventors' research collaboration networks reduce the uncertainty of firms about the match qualities of inventors prior to hiring. We estimate the effect of inventors' collaboration networks on their productivity and mobility using the U.S. patent application database. It is found that networked inventors are more productive and have longer tenure than non-networked inventors. The evidence from fixed-effect regressions shows that the higher productivity and longer tenure of networked inventors are not solely attributable to unobserved ability of inventors or unobserved characteristics of firms. These results are consistent with the job match hypothesis between inventors and firms through their collaboration networks.
\end{abstract}

Keywords: job networks, match quality, inventor, mobility, productivity, patent.

JEL Classification: J44, J63, O32.

\footnotetext{
${ }^{*}$ The authors are thankful to Daiji Kawaguchi, Jinyoung Kim, Hidehiko Ichimura, Toshiaki Iizuka, Hideo Owan, Dan Sasaki, Ryu Kanbayashi, John McBreen and seminar participants at 2008 Asian Conference on Applied Micro-Economics/Econometrics, Aoyama Gakuin University and University of Tokyo for helpful comments. The project was partially financed by the Grant-in-Aid for Young Scientists of the Japanese Ministry of Education, Culture, Sports, Science and Technolog; Japan Securities Scholarship Foundation and Inamori Foundation. All remaining errors are our own.

${ }^{\dagger}$ Department of Economics, Yokohama National University, 79-3 Tokiwadai, Hodogaya ward Yokohama 240-8501, Japan. E-mail: rn231@ ynu.ac.jp; Tel and Fax: +81-45-339-3561.

¥tamura@dpipe.tsukuba.ac.jp

§nobuyuki.HANAKI@univmed.fr and hanaki@dpipe.tsukuba.ac.jp
} 


\section{Introduction}

It is widely accepted that the mobility of inventors is an important source of knowledge transfer among research firms (e.g., Arrow, 1962; Levin, Klevorick, Nelson, Winter, Gilbert, and Griliches, 1987; Almeida and Kogut, 1999). Firms use inventors' mobility to acquire external knowledge for new innovations (Rosenkopf and Almeida, 2003; Song, Almeida, and $\mathrm{Wu}, 2003)$. Yet, it may not be obvious to firms which inventors they should hire from their large potential employee pool, because firms may face difficulty in ascertaining how well an inventor is matched with them prior to employment. Some hired inventors may be poor matches for the job they hold and thus turn out to be not as good as they initially appeared to be. Because a better job match leads to higher inventive productivity, one of the fundamental issues in the industrial organization literature is to identify a mechanism that facilitates a good match between inventors and firms. The following questions should be addressed. Which source of information do inventors and firms employ to improve the match quality? How does such a mechanism influence inventors' mobility and productivity?

Recent developments in the literature on social and economic networks may offer a clue to the above research questions. One of the most widely documented facts about job searches is that networks of personal connections, often called old-boy networks or informal job networks, can be used by employers to assess their job applicants' motivation, ability, and likelihood of success. ${ }^{1}$

Theoretical studies of informal networks in labor markets ${ }^{2}$ investigated the implications of the prevalence of informal job networks in the labor market by focusing on such functions of networks as (1) transmission of job opening information (Calvo-Armengol and Jackson, 2004; Tassier and Menczer, 2008), (2) screening and signaling employees' abilities (Saloner, 1985; Montgomery, 1991; Casella and Hanaki, 2006, 2008), that is, referrals through job networks may provide firms with information about unobserved workers' ability, allowing firms to use the information to select high-ability workers, and (3) reducing uncertainty about employee-employer match quality (Simon and Warner, 1992; Mortensen and Vishwanath, 1994), that is, referral through job networks may provide workers with information about unobserved match quality, allowing workers to self-select themselves to firms that represent a good match. This paper follows this literature and analyzes the effect of inventors' job networks on their mobility and productivity.

We use the job search model of Simon and Warner (1992) where an inventor and a firm match through a collaboration network. We posit an inventor as networked if, at the time of his employment, his collaborator (or collaborators) with whom he had worked in past research activities was (were) present at the firm. Both inventors and firms are uncertain about their match value prior to hiring. However, the match value is less uncertain for networked inventors than for non-networked inventors. A firm can infer the true match value of a potential employee if information about the person is available from past collaborators, and at the same time, an inventor who is networked with past collaborators can estimate more precisely how well (or how badly) matched

\footnotetext{
${ }^{1}$ For example, Granovetter (1995), in his survey of residents in Newton, Massachusetts, in the late 1960s, found that more than half of jobs were obtained through personal connections.

${ }^{2}$ See Ioannides and Loury (2004) for an extensive review of the literature.
} 
he is for the position offered by a potential employer. The main predictions of the model are: (1) networked inventors have higher productivity, at least initially, than non-networked inventors because a good match is more likely to occur; and (2) they have longer tenure because they are less likely to be disappointed with their revealed match value and thus are less likely to quit.

This paper investigates whether these predictions of the model hold for patentgranted inventors who have changed their employers at least once by making use of the United States patent application database provided by the National Bureau of Economic Research (NBER). We recompile the patent data by each inventor. Because the name of the patent assignee, which is typically the inventor's employer, is listed in each patent application, we can track down the companies by which each inventor had been employed over time and thus can identify the inventors' employment histories. In the process of tracing inventors' mobility, identification error, often called the "Who is Who" problem (Trajtenberg, Shiff, and Melamed, 2006), because of the possibility of multiple name spellings for the same person and the possibility of the same name for different persons, cannot be avoided. To minimize the error, we deliberately use a computer matching procedure that has been recently proposed by Trajtenberg, Shiff, and Melamed (2006). ${ }^{3}$

The main empirical findings of this paper are as follows. Comparing employment durations, networked inventors have significantly longer tenure than non-networked inventors. As for inventors' productivity, which is measured by the number of successful patent applications made in a year, networked inventors are substantially more productive than non-networked inventors. It is also found that after-job-switch productivity is substantially higher for the inventors who are networked with high-productivity collaborators than for those who are networked with low-productivity collaborators, suggesting that the collaboration network acts as a screening mechanism to select inventors' research ability. Nonetheless, even after controlling for positive association between the inventors' productivities and their collaborators' productivities, a substantial productivity advantage of networked inventors over non-networked inventors remains. Furthermore, the productivity advantage of networked over non-networked inventors declines as tenure progresses. These results are shown to be robust even after controlling for both individual and firm-specific unobserved factors. All these empirical findings can be consistently explained by the job match hypothesis that the job network reduces ex ante uncertainty about match value, although they may well be explained by an alternative hypothesis, such as the "ex post learning" hypothesis, that networked inventors learn innovation "know-how" through their past collaborators ex post, after hiring.

This paper is related to two strands of literature. First, it is related to the empirical labor literature which estimates the effects of informal job referral on workers' tenure and wage profiles. Many studies find that workers who use references have longer employment tenure than those who do not use references (Loury, 1983; Topel and Ward, 1992; Simon and Warner, 1992; Loury, 2006). In contrast, the results are mixed for the effect of job references on workers' wage profiles. Some studies present

\footnotetext{
${ }^{3}$ Recently, several papers (e.g., Agrawal, Covkburn, and McHale, 2006; Schankerman, Shalem, and Trajtenberg, 2006; Marx, Strumsky, and Fleming, 2007; Hoisl, 2007) have employed a similar identification method.
} 
evidence that workers with a referral have higher wage premiums, at least initially, than workers without a referral (Simon and Warner, 1992; Marmaros and Sacerdote, 2002). In contrast, other studies concluded that higher wages are not necessarily associated with job references. Bridges and Villemez (1986); Marsden and Hurlbert (1988) found no general or initial wage premium for referred workers. Kugler (2003) found that higher wage premiums for referred workers only exist between, not within, industrial sectors. Pellizzari (2004) found that, using the data of European Union countries, both wage premiums and penalties exist for referred workers across countries and industries. Antoninis (2006) studied the labor market of the Egyptian manufacturing sector and found that referred workers take wage penalties in the case of recruitment to low-skilled jobs, but, if workers are referred by individuals who have direct working experience with them, they can obtain wage premiums in both low- and high-skilled jobs. Finally, Loury (2006) showed that only young males who are referred by oldergeneration male relatives enjoy higher wages, but no significant job reference effect exists for other groups of workers.

Our paper departs from these empirical studies in that we study inventors who actively engage in research activities, and we estimate how the existence of personal connections influences their research productivity and employment duration after moving into a new firm. Given that our focus is on inventors, we directly estimate the effect of network references on productivities rather than wages. We also refine the definition of a job reference network. In previous studies, job references through friends, family, acquaintances and relatives are mainly considered to convey job match information. In contrast, we use inventors' research collaboration networks as a channel for job information flows.

The second strand of the literature to which this paper relates is the empirical industrial organization literature that studies the extent of the mobility of inventors and its implications for innovation. Kim and Marschke (2005) analyzed the role of patenting for firms to protect their inventive knowledge against spillovers through labor mobility. They found that firms' patenting and inventors' mobility are positively correlated. Hoisl (2007) studied the mobility of inventors by using German patent application data and found that there are simultaneous relationships between inventors' mobility and productivity. It is shown that inventors with higher productivity are less likely to move, and at the same time, movers are more productive than nonmovers. Schankerman, Shalem, and Trajtenberg (2006) studied inventors' mobility in the United States software industry and found no evidence that the quality of patents increased after their job changes. This suggests that inventor mobility does not necessarily improve the match quality between inventors and firms. While these studies focused on the relationship between inventor mobility and productivity, this paper, in contrast, studies the effects of the job search method on the mobility and productivity of inventors.

It should finally be stressed that our study draws upon the standard job search model in which a worker who is searching for a job is randomly matched with firms, and is offered the expected value of the match as a wage. This view is motivated by Jovanovic (1984) and Simon and Warner (1992) who consider the role of uncertainty in determining wages, job tenure and job turnover. Accordingly, we follow the same modeling approach in that the focus is on the forward looking behavior of workers, with "perfect competition" assumed for the firms. In the literature on job search theory, however, var- 
ious models that explicitly account for the search and matching mechanisms of workers and firms, including match formation and match dissolution, with various endogenous wage determination processes in equilibrium, have been developed and analyzed. ${ }^{4} \mathrm{Ba}-$ sically, two types of the search models leading to endogenous wage distribution can be distinguished in the literature. The first type of the models, a so called, "searchmatching-bargaining-equilibrium" model (see Pissarides, 1979, 2000), assumes that only a fraction of the surplus goes to workers in the form of a wage, depending upon the bargaining positions of two parties involved in a match. On the other hand, the second type of the models, a so called "posting-wage equilibrium" model (see Burdett and Mortensen, 1998; Postel-Vinay and Robin, 2002), assumes that firms capture the entire surplus of matches, but workers are paid wages that exceed their reservation wages because firms compete by posting wages. Such equilibrium search models have the advantage that the matching process between workers and firms are explicitly incorporated and thus considered more realistic than the "one-sided" search model on which we base our inference. However, the disadvantages are that they also require strong assumptions about the wage determination process, such as agents' bargaining power or their commitment to the posted terms of trade. Furthermore, as has been pointed out (see Eckstein and van den Berg, 2007), high quality data, not only on the worker's side data but also on the firms' side, is required for the identification of equilibrium search models. To the best of our knowledge, neither theoretical nor empirical studies have analyzed the equilibrium search behaviors of both workers and firms that use job networks for their job search or job hiring. So, one can consider our attempt, though primitive in modeling the processes of job matching and wage determination, as a starting point to empirically analyze the role of informal job networks by using a search theoretic model of the labor market. Admittedly, the extension of our model to an equilibrium search framework should be pursued through further research, hence possible extensions will be discussed in conclusion.

The rest of this paper is organized as follows. Section 2 presents the model and provides the hypotheses to be tested. Section 3 describes the dataset we use for estimation. Section 4 explains our empirical strategies and presents the estimation results. Section 5 concludes.

\section{Model}

We use the model of Simon and Warner (1992), who employed a discrete-time version of the job matching model introduced by Jovanovic (1984) to analyze the difference in wage profiles between networked and non-networked workers. While their focus is on the wages of researchers, we analyze the comparative statics of the productivity of researchers who are actively engaged in the innovation process, and the predictions are tested using patent data of the United States.

Consider a situation where inventors, who maximize the discounted sum of future wages, are searching for a job, and firms are looking for a new inventor to hire. It is assumed that an inventor and a firm are matched randomly. When matched, both the

\footnotetext{
${ }^{4}$ See Mortensen and Pissarides (1999) and Rogerson, Shimer, and Wright (2005) for recent survey of the equilibrium search models of the labor market.
} 
inventor, call him $i$, and the firm, call it $j$, are uncertain about their true match value, $\theta_{i j}$, but they receive a noisy signal, $\theta_{i j}+\varepsilon_{i j}$, of it. We assume that the noisy signal $\theta_{i j}+\varepsilon_{i j}$ and the match productivity $\theta_{i j}$, if it reveals, are commonly observed by both of the agents involved in the match, so there is no asymmetric information problem here. The true match value is individual-firm specific and assumed to be independently drawn from $N\left(\mu, \sigma_{\theta}^{2}\right)$. The amount of noise in the signal that the inventor and firm receive depends on whether the inventor's previous collaborators, with whom he had worked on past research activities, were employed at the firm at the time of the match. We call an inventor networked $(k=N)$ if his previous collaborators are present at the firm, and non-networked $(k=O)$ otherwise. The match value is less uncertain for networked inventors than for non-networked inventors, and thus there is less noise in the signal for networked inventors. In particular, we assume that white noise $\varepsilon_{i j}$ is independently and identically distributed following $N\left(0, \sigma_{\varepsilon, k}^{2}\right)$ with $\sigma_{\varepsilon, N}^{2}<\sigma_{\varepsilon, O}^{2}$. The reduction in the noise is due to the possibility of a better information transmission between the inventor and the firm the previous collaborators at the firm facilitate. We assume that an inventor is networked to a firm with an exogenously given probability, $p$.

We assume that the market is competitive so the firms make zero expected profit. ${ }^{5}$ The firm offers the expected productivity of the inventor, $q_{i j}$, based on the observed signal and its quality as the entry wage. If the inventor accepts the offer, he is hired and works at the firm. If he rejects the offer, he enters the next period searching for a job and is matched to another firm. Once the inventor works at the firm, we assume that the true match value, $\theta_{i j}$, is revealed and is known by both inventor and firm immediately. The firm offers the true match value to the inventor as the future wage, and the inventor decides whether to stay at the firm or to leave and look for a new job. Therefore, if inventor $i$ stays at the firm, the wage profile offered by the firm $j$ is

$$
w_{i j t}= \begin{cases}q_{i j}=\mathrm{E}\left(\theta_{i j} \mid \theta_{i j}+\varepsilon_{i j}\right) & \text { if } t=1 \\ \theta_{i j} & \text { if } t \geq 2 .\end{cases}
$$

It should be noted that, because the match value is firm specific, an inventor will find a different match value if he changes firms. In what follows, the subscripts $i$ and $j$ are suppressed for notational simplicity. Instead, we introduce subscript $k$ to denote whether inventor is networked $(k=N)$ or not $(k=O)$ at the firm.

The normality assumptions of $\theta$ and $\varepsilon_{k}$ imply, according to the Bayes' rule, that the posterior distribution of the estimate on the productivity $\theta$ follows $N\left(q_{k}, s_{k}^{2}\right)$ with $s_{k}^{2}=\left(1 / \sigma_{\theta}^{2}+1 / \sigma_{\varepsilon, k}^{2}\right)^{-1}$ and $q_{k}=s_{k}^{2}\left[\mu / \sigma_{\theta}^{2}+\left(\theta+\varepsilon_{k}\right) / \sigma_{\varepsilon_{k}}^{2}\right]$. In what follows, we used $F$ to dnote the CDF of the posterior distribution $N\left(q_{k}, s_{k}^{2}\right)$.

The inventor's decision can be solved backwardly. Assume that he was employed at the end of period $t=1$. Let $J(\theta)$ be the present value of staying in the job. The

\footnotetext{
${ }^{5}$ The assumption of "perfect competition" can be interpreted as a situation in which workers obtain the entire surplus generated by the match. This is considered as an extreme case of the equilibrium search models where, due to the presence of search and matching frictions, employers are assumed to pay their employees wages lower than their marginal productivities. A possible extension of our model along the line of these equilibrium approaches will be discussed in the conclusion.
} 
present value of accepting the offer $\theta$ is given by $\theta+\beta J(\theta)$, where $\beta$ is the discount factor. If he rejects it, he receives nothing, and becomes unemployed in the next period. Let $W$ be the present value of being unemployed at the beginning of a period. Time invariant match value at a the firm implies that

$$
J(\theta)=\max \{\theta+\beta J(\theta), \beta W\}
$$

The decision to stay or to leave the job at the end of period $t=1$ is characterized by a reservation value, $\theta^{*}$, below which the inventor leaves the job. $J(\theta)$ is, therefore:

$$
J(\theta)=\left\{\begin{array}{ll}
\frac{\theta}{1-\beta} & \text { if } \theta \geq \theta^{*} \\
\beta W & \text { if } \theta<\theta^{*}
\end{array},\right.
$$

where the reservation value, $\theta^{*}$ which does not depend on whether the inventor is networked or not, is given by $\theta^{*}=\beta(1-\beta) W$.

The probability that an inventor leaves at the employed firm, which is given by $\int^{\theta^{*}} d F\left(\theta \mid q_{k}, s_{k}^{2}\right)$, is shown to be an increasing function of $\sigma_{\varepsilon k}^{2}$. Because $\sigma_{\varepsilon N}^{2}<\sigma_{\varepsilon O}^{2}$, not-networked inventors are more likely to leave the employed firm than networked inventors. Therefore, we obtain the following proposition:

Proposition 1 Networked inventors have longer employment duration than non-networked inventors.

Let us turn to investor's decision whether to accept initial offer, $q$. The expected present value of the future wage flow from accepting initial offer $q$ for type $k$ inventor is given by $q+\beta \mathrm{E}[J(\theta) \mid k]$. Therefore, the value of accepting the offer $q$ for type $k$ inventor is:

$$
\begin{aligned}
V(q \mid k) & =\max \{q+\beta \mathrm{E}[J(\theta) \mid k], \beta W\} \\
& =\max \left\{q+\beta \int J(\theta) d F\left(\theta \mid q_{k}, s_{k}^{2}\right), \beta W\right\} .
\end{aligned}
$$

Since the value function $V(q \mid k)$ is monotonically increasing in $q$, the decision whether to accept the job offer for type $k$ inventor is characterized by the reservation wage $q_{k}^{*}$ :

$$
q_{k}^{*}+\beta \int J(\theta) d F\left(\theta \mid q_{k}^{*}, s_{k}^{2}\right)=\beta W .
$$

Given $J(\theta)$ shown in equation (3) implies:

$$
q_{k}^{*}=\theta^{*}-\frac{\beta}{1-\beta} \int_{\theta^{*}}\left(\theta-\theta^{*}\right) d F\left(\theta \mid q_{k}^{*}, s_{k}^{2}\right) .
$$

Because the second term of the right-hand side of equation (6) is positive, the reservation value in the second period is always larger than the reservation wage in the first pe$\operatorname{riod}\left(\theta^{*}>q_{k}^{*}\right)$. In addition, while the reservation value $\theta^{*}$ does not depend on whether 
the inventor is networked or not, the reservation wage $q_{k}^{*}$ does. It can be easily shown that $\sigma_{\varepsilon, N}^{2}<\sigma_{\varepsilon, O}^{2}$ implies $q_{N}^{*}>q_{O}^{*}$, which means that the first period reservation wage of networked inventors is higher than not-networked inventors. Given $q_{N}^{*}>q_{O}^{*}$, the following result is obtained about the inventor's mean productivity in the first period:

Proposition 2 Networked inventors exhibit a higher initial productivity than non-networked inventors, on average.

This follows from the fact that the mean productivity for type $k$ inventors, $\mathrm{E}\left(\theta \mid q>q_{k}^{*}\right)$ is an increasing function of $q_{k}^{*}$. ${ }^{6}$

We finally turn to the mean productivity of type $k$ inventors in the second period. Since the inventors whose match values are less than $\theta^{*}$ have left the firm, the mean productivity of type $k$ inventors in the second period is given by $\mathrm{E}\left(\theta \mid q>q_{k}^{*}, \theta>\theta^{*}\right)$. One can show that the mean productivity weakly increases with the tenure, i.e.,

$$
\mathrm{E}\left(\theta \mid q>q_{k}^{*}\right) \leq \mathrm{E}\left(\theta \mid q>q_{k}^{*}, \theta>\theta^{*}\right)
$$

But the productivity growth is different between two types of inventors, which can be best illustrated in the limiting case where the information transmission by the inventor's past collaborators approaches zero, $\sigma_{\varepsilon N}^{2} \rightarrow 0$, while $\sigma_{\varepsilon O}^{2}$ is strictly positive for the notnetworked inventors. In such a case

$$
\mathrm{E}\left(\theta \mid q>q_{N}^{*}\right)=\mathrm{E}\left(\theta \mid q>q_{N}^{*}, \theta>\theta^{*}\right)
$$

That is, we do not observe any productive growth for networked inventors, while we do for non-networked inventors as shown above. Therefore, we have the following result:

Proposition 3 Networked inventors have lower productivity growth than non-networked inventors as tenure increases, so the initial productivity advantage of networked inventors over non-networked inventors disappears as tenure increases.

\section{Data}

We base our analysis on the NBER Patent Data File. ${ }^{7}$ This dataset covers all the patent applications between 1963 and 1999 and those granted up to December 1999. For each patent, the list of inventors, assignee, and year of application are recorded, along with other information such as addresses of inventors, the type of assignee, and the technological category of the patent. We supplement the month of the patent application with the USPTO PatentBIB database. The NBER Patent Data File contains the patent citations for patents that were applied for after 1975. Because the citation information is required to identify unique inventors, as described below, the patents that were applied for before 1974 are excluded from our sample. It should be noted that many patents that

\footnotetext{
${ }^{6}$ For the derivation of this and the following equation (7), see the working paper version of this paper

${ }^{7}$ For detailed information, see Hall, Jaffe, and Trajtenberg (2001).
} 
were applied for in 1998 and 1999 are missing from the database because there is often a lag of a few years before patents are granted. ${ }^{8}$ Therefore, we use the patents that were applied for between 1975 (the first year in which citation information is available) and 1997 (the latest year in which the effect of truncation is not substantial) in our analysis.

\subsection{Employment History}

In order to analyze the mobility of inventors, we are required to identify, for each inventor in the dataset, his affiliation over time from the information contained in the patents. This, however, is not a simple task because the same inventor may have his name spelled differently across his patents, or different inventors may have the same name. To overcome this difficulty, we follow the computerized matching procedure (CMP) proposed by Trajtenberg, Shiff, and Melamed (2006) in identifying inventors. In doing so, CMP utilizes not only the name of inventors recorded in the patents, but also patent citations, and inventors' addresses, while allowing for the possibility of spelling errors in names. ${ }^{9}$ In addition, to increase the accuracy of matching individual inventors, we focus on the inventors whose addresses are in the United States.

Once inventors are identified, the history of granted patents is generated for each inventor. Furthermore, based on the application dates and assignees of those patents, we create each inventor's employment history. Our basic strategy is to consider the longest possible employment durations by assuming that an inventor was employed by an assignee for all the period during which he applied for patents assigned to the assignee.

It should be noted, however, that if companies undergo a merger or acquisition, the acquired company appears under the name of the acquiring company after the official date of merger. To avoid identifying changes in the assignee's name because of M\&A as changes in the inventor's employer, we supplement our data using the SDC Platinum, the Worldwide Mergers and Acquisitions Database, issued by ThomsonReuters. Among all the M\&As since 1979 that are reported in SDC Platinum, we select the cases where the acquiring company obtains all the stock of the target company. We then consider those two companies to be in a parent-subsidiary relationship and treat them as one company after the merger. We also subsample the inventors whose lists of assignees are categorized as private companies located in the United States. ${ }^{10}$

Let us now describe, in detail, how we construct the employment histories for inventors. We first list all the assignees of the patents listed in the individual history. Then, given the listed assignees, we take the earliest and the latest patent application dates, and consider the interval between the two dates as a candidate job spell (CJS), which is considered to be the longest possible employment duration. ${ }^{11}$ After identify-

\footnotetext{
${ }^{8}$ For example, Hall, Jaffe, and Trajtenberg (2001) showed that the average time lag between the application and grant date in the late 1990 s was 1.8 years.

${ }^{9}$ For the details of this procedure, see the Appendix A of the working paper version of this paper.

${ }^{10}$ To identify the type of assignees listed in the patent application data we utilize the corporate and noncorporate name matching results available from Bronwyn Hall's web page of The Patent Name-Matching Project (http://elsa.berkeley.edu/ bhhall/pat/namematch.html). In this analysis, we exclude assignees categorized as government institutions, universities and hospitals.

${ }^{11}$ We allow $C J S$ s whose spell length is zero, which happens when an inventor applies for all the patents from an assignee within a month.
} 
ing all the $C J S \mathrm{~s}$, we (1) eliminate all the $C J S$ s that are contained entirely within a longer $C J S$, and then (2) eliminate the $C J S$ s that overlap with each other. We use criterion (1) because we assume that those patents that have created such shorter $C J S$ s are the result of inter-assignee collaborations. In addition, we follow criterion (2) because we are unable to determine the exact time when the inventor moved from one assignee to another. These criteria are quite stringent, yet we have chosen to follow them because the determined employment durations are defined as clearly as possible. ${ }^{12} \mathrm{We}$ define job spells using all the remaining $C J S$ after the criteria are applied.

The procedure is summarized in Figure 1, which illustrates an inventor's $C J S \mathrm{~s}$ (given by line segments) and the time of patent applications (given by solid circles). We have $C J S_{j}$ for assignee $j=1, \cdots, 5$, and patent application, $P_{j k}$, the $k$ th patent application of assignee $j$. In the diagram, five $C J S$ s are shown by segments in different layers for different assignees on the vertical axis. According to the criteria described above, only $C J S_{1}$ and $C J S_{2}$ are considered as job spells (given by arrow segments). $C J S_{3}$ is not a job spell because it is contained in $C J S_{2}$ (criterion (1)). Furthermore, $C J S_{4}$ and $C J S_{5}$ are not job spells because they overlap with each other (criterion (2)).

\subsection{Job Network}

We obtain information concerning job networks from the patent collaboration histories of colisted inventors. In doing so, we define the set of collaborators of inventor $i$ on date $t$ by all the inventors who are colisted on the patents that inventor $i$ applied for (and were later granted) before date $t$. For example, for the inventor shown in Figure 1, the set of collaborators on date $P_{21}$ constitutes all of the coinventors listed in the three patents applied for during spell 1 (those applied for on $P_{11}, P_{12}$, and $P_{13}$ ). Given the set of his collaborators, we identify collaborator $i$ as networked if at least one of his collaborators is employed by the same firm at the beginning of inventor $i$ 's job spell. If this is not the case, inventor $i$ is considered to be non-networked. The past collaborator who is networked with the inventor is called the referee because he is assumed to provide a job reference on the inventor to the potential employer. The referee, in other words, is considered as a go-between researcher through whom both the inventor and the firm are "linked", and we obtain match quality information.

One feature of the job network construction concerns the presumption of information flows between inventors and firms through referees. Given the growing importance of teams in research in science nowadays, it seems natural to assume that past research collaboration provides rich information for both inventors and firms to judge the job match of an inventor. Yet, unfortunately, such information cannot be directly observed in our data, so that we only speculate as to how the information flows between inventors and firms. We are thus obliged to point out that the interpretation of the empirical results hinges upon the validity of the assumption of the information flow. Although the principal message of this paper is that differences in inventors' mobility and innovation productivity can be explained by the job match mechanism, it is possible to offer alternative explanations. We provide further discussion of this issue in a later section.

Finally, it is possible that more recently established collaborations generate more

${ }^{12} \mathrm{~A}$ similar assumption is made in previous studies (e.g., Hoisl, 2007). 
meaningful job information. Therefore, in the analyses below, we also consider more restricted sets of collaborators; namely, in addition to the set of collaborators defined above (we call these overall collaborations), we also consider sets of collaborators at time $t$ based on the successful patents that have been applied for within 12, 24, and 36 months prior to date $t$.

\subsection{Summary Statistics}

The numbers of identified $C J S$ s and job spells are presented in Table 1. Given the data construction procedure presented above, we have 271,348 inventors in total. Because only inventors who experienced a job switch at least once are analyzed, all inventors who stayed with only one company are excluded from the sample. Then we have 51,896 inventors who experienced at least one job switch, which is about $20 \%$ of the original sample. For those inventors we have 120,826 CJSs. ${ }^{13}$ After eliminating the overlapped $C J S$ s according to criteria (1) and (2), we have 115,307 job spells, which represent $95 \%$ of the original $C J S$ s. As for the distribution of the job spells, about 9 $\%$ of the job spells are originated by networked inventors. If the collaboration network is restricted to 12,24 , or 36 months, the percentages are $2.20 \%, 4.41 \%$, and $5.89 \%$, respectively.

\section{Empirical Results}

In this section, we examine the model predictions about employment duration and patent productivities. Table 2 presents the summary statistics. The employment duration of an inventor in one company is measured by the job spells (in months) constructed by the procedure above, and patent productivity is measured by the number of successful patent applications made in one year. ${ }^{14}$ Comparing networked and nonnetworked inventors, the former have longer mean and median employment durations than the latter. In particular, the median statistics imply that it takes about eight years (six years) for half of the networked (non-networked) inventors, respectively, to leave firms. As for inventors' patent prolificacy, it is shown that networked inventors are more productive than non-networked inventors. After the job change, on average, networked inventors produce more than one patent a year while non-networked inventors produce less than one patent a year.

\subsection{Employment Duration Results}

Proposition 1 suggests that networked inventors, with relatively better match values, are less likely to leave firms than non-networked inventors. Figure 2 plots the survival

\footnotetext{
${ }^{13}$ It should be noted that, in order to construct the $C J S$ s, we exclude the first $C J S$ s and use only subsequent $C J S$ s of inventors because no inventors are networked for their first $C J S$ s.

${ }^{14}$ We also considered a productivity measure that controls for the innovation quality of each patent. Given the idea that more important patents are cited more frequently, we defined a quality-adjusted productivity measure by the number of patent applications weighted by the number of times that each patent is cited by other patents. A potential problem of this productivity measure, however, is in the fact that the number of citations is severely truncated, and thus patent quality is underestimated in more recent years.
} 
curves for employment duration after job transition for networked and non-networked inventors. Because the job spell data are arbitrarily censored, ${ }^{15}$ we employ a nonparametric maximum likelihood estimator for interval-censored data proposed by Turnbull (1976). It is shown that the employment duration is almost uniformly longer for networked inventors than for non-networked inventors. We also use the log-rank statistic of (Peto and Peto, 1972) to test the equality of the survival functions between the networked and non-networked inventors for various definitions of the collaboration network, and find that all the tests are strongly rejected at the $1 \%$ significance level. ${ }^{16}$

We estimate hazard regression models of inventors' job turnover, controlling for their characteristics. The hazard function is given by a Weibull specification as follows: $h\left(t_{i f} \mid X_{i f}\right)=\exp \left(X_{i f} \beta+\delta N E T_{i f}\right) \alpha t_{i f}^{\alpha-1}$ where $t_{i f}$ is inventor $i$ 's employment duration at firm $f$, and $X_{i f}$ is a vector of time-invariant individual characteristic variables. The definitions of the variables are presented in Appendix. Among the control variables, the most important one is the network dummy, $N E T_{i f}$, which takes a value of one if inventor $i$ is a networked inventor at firm $f$ and zero otherwise. According to Proposition 1 , we expect that $\delta<0$, that is, networked inventors are less likely to leave their employed job than non-networked inventors. As other regression variables, we include research field dummies, past productivities, and research experience, all of which are used to control for the inventor's research ability.

Table 3 presents the estimation results of the hazard regression model. As in the survival curve analysis, interval censoring is taken into account for estimation. We use the total number of patents previously applied for in column (1), and use the average number of patents previously applied for in column (2) to control for the inventor's ability, respectively. In both specifications, the coefficient $\delta$ is negative and statistically significant, and thus the presence of previous collaborators at the new firm significantly decreases the hazard of leaving the job. Therefore, the networked inventors are likely to stay longer at the firm than the non-networked inventors. In columns (3)-(5), we use various definitions of networked inventors that limit the intervals after the collaborations were made. The estimates of the coefficients of network dummies are significantly negative in all specifications. These estimates imply that networked inventors are about $40 \%$ less likely to leave the job than non-networked inventors.

\subsection{Productivity Results}

Our model presents two main empirically testable hypotheses about inventors' productivity. The first hypothesis is given by Proposition 2, that networked inventors have a higher initial productivity than non-networked inventors on average. The second hypothesis is given by Proposition 3, that within-firm productivity growth rates are different between non-networked inventors and networked inventors; in particular, the former have a steeper productivity-tenure profile than the latter. Thus, the initial productivity advantage of networked inventors over non-networked inventors disappears as tenure progresses.

\footnotetext{
${ }^{15}$ Our job spell data are arbitrarily censored because the value lies in an interval, instead of being observed exactly.

${ }^{16}$ For detailed test results, see the working paper version of this paper.
} 
To examine these hypotheses, we introduce a regression framework. The dependent variable of the regression is the number of successful patent applications made by an inventor in one year, which is considered to be a measure of the inventor's productivity. Because the dependent variable is an integer variable with many zeros and ones, we use a Poisson-based specification as in Hausman, Hall, and Griliches (1984); Hall and Ziedonis (2001). Consider an inventor $i$ who works at firm $f$. We assume that the expected number of patents, $P_{i f t}$, applied for by the inventor in year $t$, conditional on the characteristics of the inventor and firm, is given by:

$$
\mathrm{E}\left(P_{i f t} \mid X_{i f t}, N E T_{i f}\right)=\exp \left(\alpha+X_{i f t} \beta+\rho N E T_{i f}\right),
$$

where $X_{i f t}$ is a vector of individual-firm time-specific variables.

A key variable in our specification above is the network dummy, $N E T_{i f}$. The scalar coefficient $\rho$ of the network dummy can be interpreted as the match premium for networked inventors over non-networked inventors. According to Proposition 2, the networked inventors can obtain information about their match values with their potential employers through their collaboration network, and thus have better initial match values than non-networked inventors. We thus expect that the match premium is positive in the early stage of tenure.

As mentioned in the introduction, however, the role of collaboration networks may not be confined to reducing match uncertainty between inventors and firms. It is argued in previous studies that network references may act as a screening device in the selection of high-ability workers. Knowing that referees tend to refer others who are similar to themselves, firms have incentives to select inventors who were referred by highproductivity referees rather than those who were referred by low-productivity referees. Therefore, if the collaboration network works as the screening device, the productivity of a networked inventor will be positively correlated with the productivity of the referee who referred the inventor to the firm.

To capture the screening effect through the collaboration network, the regression variables include the productivity of the referee inventor who referred inventor $i$ to firm $f$ (we call this the referee's productivity). We measure the referee's productivity by the total number of patents that he applied for at firm $f$ before inventor $i$ switched to the firm. For non-networked inventor $i$, because he was not referred by anybody at the job switch, the referee's productivity variable is set to be zero. If the screening mechanism works for the collaboration network, it is predicted that the referee's productivity is positively related to networked inventor $i$ 's productivity, and thus the sign of the estimated coefficient of the referee's productivity is positive. It should be noted that the screening effect is not captured by the match premium $\rho$ of the coefficient of $N E T_{i f}$. The job match hypothesis implies that the match premium is positive, $\rho>0$, no matter who is the referee. In other words, a networked inventor was able to obtain information about his match value with the potential employer, even through a referee who exhibits low patent productivity. Therefore, the job match hypothesis alone cannot explain positive association in productivity between the referee inventors and referred inventors.

As other regression variables for $X_{i f t}$, we include research experience and withinfirm research experience, respectively, to control for the effect of experience on patent 
productivity. The past productivities are also included to take into account the inventor's innate research ability, as was done for the hazard regression. In addition, the firm's patent productivity is used to control for the research capacity of the firm. It is expected that the higher the firm's research capacity, the more patents the firm produces, and vice versa. ${ }^{17}$ Finally, following the previous literature, (e.g., Hall and Ziedonis, 2001), we include annual dummies, which account for the growth of patenting propensities, and the first-year tenure dummy, which takes a value of one if the inventor is in the first year of employment. The variable is included to control for our job spell construction property, that at least one patent is included in the first tenure year. Again, detailed definitions of these control variables are found in Appendix.

In the following estimation we take into account the time-invariant unobserved individual factors. If such unobserved factors of inventors are not explicitly controlled for, the estimated productivity difference between networked and non-networked inventors can be explained by differences in their unobserved factors, such as ability. For that purpose we augment the baseline regression model (9) by adding an individual time-invariant fixed effect:

$$
\mathrm{E}\left(P_{i f t} \mid X_{i f t}, N E T_{i f}\right)=\exp \left(\alpha_{i}+X_{i f t} \beta+\rho N E T_{i f}\right) .
$$

The fixed effect, $\alpha_{i}$, captures inventor $i$ 's unobserved heterogeneity that affects his research productivity. One final concern about the Poisson regression model (10) is possible correlation of productivities, $P_{i f t}$ and $P_{j f t}$, between inventors $i$ and $j$ within firm $f$. This type of within-group correlation is typically explained by an unobserved group-specific factor, say, $\alpha_{f}$, that is common to inventors $i$ and $j$ who work in the same firm $f$. It is known (see Wooldridge, 2006, for example) that the fixed-effect Poisson regression model is robust to this type of within-group or cluster correlation under the assumption that the variables, $X_{i f t}$ and $N E T_{i f}$, are strictly exogenous conditional on the unobserved factors $\alpha_{i}$ and $\alpha_{f}$. ${ }^{18}$ Yet, the variance-covariance matrix is misspecified in this case. Therefore, we compute a cluster-robust variance-covariance matrix using the bootstrap method with 50 replications, and report the cluster-robust standard errors for the parameter estimates.

Table 4 presents the estimates of the selected covariates of the Poisson regression model (10). ${ }^{19}$ We again restrict samples to the inventors who experienced at least one job transition because no inventor is recruited via his collaboration network for the first job. It thus implies that we estimate the effect of referrals on inventors' productivity after switching firms. ${ }^{20}$ As should be clear from the above discussion, the data have an unbalanced panel structure with individual-firm-year being the unit of analysis.

In Table 4, column (1) shows the estimation results using the network dummy constructed from the overall collaboration network. It is found that the estimate of the

\footnotetext{
${ }^{17}$ Often the research capacity of a firm is measured by its R\&D expenditure. We do not use it here because in our sample there are firms that are not listed on the stock market and such data are not available.

${ }^{18}$ We relax the assumption of conditional exogeneity in Section 4.3 where we check the robustness of the estimation results.

${ }^{19}$ The estimates of all the covariates are available from the author upon request.

${ }^{20}$ The effect of network job referrals on the first employment productivity of workers, although they are not necessarily inventors, is analyzed by Simon and Warner (1992); Loury (2006).
} 
match premium of the networked inventors, $\rho$, is positive and statistically significant. Columns (2)-(4) present the estimation results that consider collaborations only from limited intervals before the job switch. It is also consistently found that the estimated values of $\rho$ are positive and statistically significant. All these findings confirm that networked inventors are more productive than non-networked inventors. More interestingly, the match premium increases as the coverage period of collaboration networks becomes shorter. This suggests that better job matches are more likely to occur between inventors and firms if referrals are based on more recent collaborations. These findings are consistent with our view that the collaboration network is a method by which agents get information about unobserved match quality, and the more recent the information is, the more certain they are about the quality of their match. The estimation results also show that the coefficients of the referee's productivity are positive and statistically significant, suggesting that inventors who were referred by higher-productivity referees tend to be more productive than those who were referred by lower-productivity referees. This suggests that firms may examine the referee's productivity to select highability inventors among potential employees. Nevertheless, the fact that a substantial match premium remains after controlling for the network screening effect seems to support the job match hypothesis. These findings thus indicate that the collaboration network simultaneously has two roles: one is to provide firms with the information needed to screen an inventor's ability, and the other is to provide firms and inventors with information about their match quality.

As for the other control variables, many of the estimates confirm our prior expectation. As one expects, the coefficients of past patent productivity are positive and statistically significant, suggesting that the inventors who had applied for more patents tended to produce more patents after their job change. Furthermore, the coefficients of firm patent productivity are, as expected, positive and statistically significant. It is also shown that there is a strong positive relationship between an inventor's productivity and his total research experience, although the relationship is less evident between productivity and within-firm research experience.

We now turn to the second hypothesis, that within-firm productivity growth is different between networked and non-networked inventors. To examine this hypothesis, we add the interaction terms of the network dummy and tenure dummies to the regression model (10). The regression model is then given by:

$$
\mathrm{E}\left(P_{i f t} \mid X_{i f t}, N E T_{i f}\right)=\exp \left(\alpha_{i}+X_{i f t} \beta+\sum_{k=1}^{K} \rho_{k}\left(N E T_{i f} \cdot \text { Tenure }_{i f t k}\right),\right.
$$

where Tenure $_{i f t k}$ is the $k$ th tenure year dummy for inventor $i$ at firm $f$, and takes a value of one if inventor $i$ is employed in the $k$ th year by firm $f$. In this within-firm productivity growth regression, the coefficient $\rho_{k}$ of the interaction term captures the productivity premium for networked inventors over non-networked inventors observed in the $k$ th tenure year. A positive value of $\rho_{k}$ means that the networked inventors have a higher productivity than non-networked inventors in tenure year $k$. As can be shown easily, $\sum_{k} \rho_{k}=\rho$. Although the theoretical model considered above assumes that agents learn about the true match value after one period, such learning may take 
place over several years in reality. Therefore, given the hypothesis that within-firm productivity growth is faster for non-networked inventors than for the networked inventors, we predict that the coefficient $\rho_{k}$ is weakly decreasing with tenure year $k$, i.e., $\rho_{1} \geq \rho_{2} \geq \cdots \geq \rho_{K}$

In Figure 3, the estimated $\rho_{k}$ s are plotted up to 15 tenure years for the network dummies constructed from the overall collaborations (a) and from within-12-month collaborations (b). ${ }^{21}$ The estimated $\rho_{k} \mathrm{~s}$ are positive and statistically significant at the $5 \%$ level for the first four to five tenure years. It is apparent that the magnitude tends to decrease globally as tenure year $k$ increases, although the pattern is not necessarily uniform. Therefore, they seem to be consistent with the job match hypothesis that non-networked inventors have a steeper tenure-productivity profile than networked inventors, and the initial productivity advantage of the former over the latter diminishes with tenure years.

Of course, the observed nonuniformity of $\rho_{k}$ cannot be explained by our model, which predicts that $\rho_{k}$ decreases uniformly as $k$ changes. In a later section, we discuss an alternative story that might be compatible with the estimation results.

\subsection{Robustness Check}

The estimation results presented above indicate that the positive match premium of networked inventors is consistent with our story that the references through collaboration networks may create better matches between inventors and firms. However, it is possible to provide alternative explanations for such a story.

First, consider the cost of patent production per inventor. Because it may decline with the number of coauthors per patent, inventors who tend to work in groups or collaborate on projects might appear to be more productive than those who do not. This is simply because they have many coauthors and thus devote relatively less time to produce one patent. This problem may occur when networked inventors are more likely to work on projects than the non-networked inventors. If this happens, networked inventors appear to be more productive than the non-networked inventors, not because of their higher match value, but because of their sheer tendency to work in groups.

Second, we should carefully control for unobserved firm-specific factors that may produce a positive correlation between productivity and collaboration. For example, if an inventor is working in a large firm, his patent productivity is enhanced by, say, his employer's large research potential. However, at the same time, his previous collaborators are likely to be hired by the same company that he now works for. Hence, if large companies provide both resources and collaborators, networked inventors may exhibit higher productivity than non-networked inventors, but it is not caused by the improved match quality through the collaboration network as we have maintained.

To examine the first alternative hypothesis, we take care of the possibility that the patent productivity is "inflated" by coauthorships. Assuming that the coauthors contribute equally to patent production, individual contribution by each inventor to each patent is given by the inverse of the number of coauthors of the patent. Therefore,

\footnotetext{
${ }^{21}$ The estimates other than the coefficient $\rho$ s are shown overall to be quantitatively similar to those of the productivity regressions that are presented in Table 4 . The full estimation results are available from the author upon request.
} 
coauthorship-adjusted productivity is given by the annual sum of an inventor's patent contributions per coauthor. More precisely, suppose that inventor $i$ applied for a total of $M_{i t}$ patents in year $t$. Let $N_{m}$ be the number of coauthors of the $m$ th patent for $m=1, \cdots, M_{i t}$. Then, the coauthorship-adjusted productivity of inventor $i$ in year $t$ is given by $P_{i t}=\sum_{m=1}^{M_{i t}} 1 / N_{m}$. Using this "weighted" productivity measure as the dependent variable, we re-estimate the regressions.

We examine the second alternative hypothesis by explicitly controlling for unobserved firm-specific factors that may influence the employees' productivity. Consider the following "two-way" fixed effect model as a linear regression model: ${ }^{22}$

$$
\mathrm{E}\left(P_{i f t} \mid X_{i f t}, N E T_{i f}\right)=\alpha_{i}+\alpha_{f}+X_{i f t} \beta+\rho N E T_{i f},
$$

where $\alpha_{i}$ is the individual-specific fixed effect and $\alpha_{f}$ is the firm-specific fixed effect. We now assume that the fixed effects, $\alpha_{i}$ and $\alpha_{f}$, are correlated with the covariates, $X_{i f t}$ and $N E T_{i f}$. Given this specification, first-differencing can eliminate the timeinvariant individual-specific fixed effect $\alpha_{i}$. Suppose that inventor $i$ worked at firm $f$ at time $t$ and worked at firm $g$ at time $t+1$. Then, the resulting time-differenced linear regression with the error term $u_{i f g}$ is given as follows:

$$
\Delta P_{i f g}=\alpha_{f g}+\Delta X_{i f g} \beta+\rho \Delta N E T_{i f g}+u_{i f g},
$$

where $\Delta P_{i f g}=P_{i(t+1) g}-P_{i t f}, \Delta X_{i f g}=X_{i(t+1) g}-X_{i t f}$, and $\Delta N E T_{i f g}=$ $N e t_{i f}-N e t_{i g}$. The parameter $\alpha_{f g}$ is given by the difference between the two firmspecific fixed effects $\left(\alpha_{g}-\alpha_{f}\right)$. Then we apply the usual "group mean-differencing" to eliminate the group-invariant firm fixed effect, $\alpha_{f g}$, and obtain the "within-group" estimator from the following regression:

$$
\Delta P_{i f g}-\overline{\Delta P_{f g}}=\left(\Delta X_{i f g}-\overline{\Delta X_{f g}}\right) \beta+\rho\left(\Delta N E T_{i f g}-\overline{\Delta N e t_{f g}}\right)+\left(u_{i f g}-\overline{u_{f g}}\right),
$$

where $\overline{\Delta P_{f g}}$ is the group average of the difference in productivity, $\Delta P_{i f g}$, over all inventors who switch from company $f$ to $g$. The other group-average variables are constructed accordingly.

Table 5 presents estimates of the network effect, $\rho$, from the productivity regression with "coauthor-weighted" productivity being the dependent variable. Panel A presents the estimation results controlling for only the individual fixed effect, and panel $\mathrm{B}$ presents the estimation results controlling for both individual and firm fixed effects. The estimates of panel $\mathrm{B}$ are based on the two-way fixed-effect regression model (12). ${ }^{23}$. We also estimate the fixed-effect regression model using productivity "unweighted" by coauthorship. We find that the estimation results are overall the

\footnotetext{
${ }^{22}$ At first look, one may think a "two-way" fixed effect model works such as $\mathrm{E}\left(P_{\text {ift }} \mid X_{\text {ift }}, N E T_{i f}\right)$ $=\exp \left(\alpha_{i}+\alpha_{f}+X_{i f t} \beta+\rho N E T_{i f}\right)$ works. However, the conditional maximum likelihood estimation method proposed by Hausman, Hall, and Griliches (1984) cannot be applied to this "two-way" fixed-effect model. This is simply because there exists no appropriate statistic on which the likelihood function should be conditioned. Thus, we need to use a different strategy to control for both individual and firm fixed effects at the same time in the population regression model.

${ }^{23}$ The full estimation results are available form the author upon request.
} 
same. ${ }^{24}$ Because the dependent variables of both the regressions are no longer integer valued, we can use the linear regression models instead of the Poisson regression models. The results in columns (1)-(4) show that, for all specifications of network recruitment dummies, the match premiums are again positive and statistically significant. Thus, we find solid evidence that, on average, networked inventors produce more patents than non-networked inventors after their job change.

Figure 4 plots the estimated $\rho_{k}$ s from the regression models with interaction terms of the network dummy and tenure dummies. The estimates are obtained from the linear regression model, analogous to the regression model of the interaction terms (11), with one-way individual fixed effect (solid line) and with two-way individual and firm fixed effects (dashed). For both regressions, the dependent variables are coauthor-weighted productivity, and the network dummies are constructed from within-12-month collaborations. ${ }^{25}$

As presented, the pattern of estimated $\rho_{k} \mathrm{~s}$ is very similar to that from the previous Poisson regression models. Overall, the estimated $\rho_{k}$ s decline as tenure year $k$ increases, although the $\rho_{k}$ s are positive and statistically significant at least for the first several tenure years. Hence, we may be able to conclude that the productivity advantage of networked inventors over non-networked inventors declines as tenure years increase and eventually becomes negligible. It is thus shown that this may not be just an artifact caused by inventors' group-work tendency, nor by firm-specific unobserved factors.

\section{Conclusion}

This paper used a simple model of job search and learning about match productivity, and tested the model's predictions using panel data of affiliations and productivities of inventors constructed from the NBER parent database. The empirical analysis seems to support the prediction of the theoretical model. It is found that networked inventors who moved to companies where their research collaborators were employed had significantly longer tenure than non-networked inventors who moved to companies with which they had no personal connections. Moreover, the former group produced substantially more patents than the latter group several years after their job switches, but the productivity gap between the two groups had declined as tenure years increased. These findings seem to be consistently explained by the job match story that inventors and firms can discover match quality through job networks, ex ante, that is, before hiring. Interestingly, there is also evidence that job networks operate as a screening mechanism, and that they enable firms to extract information about the potential employees' unobserved ability through their referees' observed abilities. Finally, fixedeffect regression results showed that unobserved individual and firm characteristics cannot explain all of the productivity differences between networked inventors and non-networked inventors.

While the presented empirical evidence leads us to conclude that collaboration networks reduce the uncertainty in match quality, there are several qualifications to keep

\footnotetext{
${ }^{24}$ The estimation results are available from the author upon request.

${ }^{25} \mathrm{We}$ also plotted the estimated $\rho_{k}$ using different collaboration intervals, and found similar patterns.
} 
in mind. First, as we remarked previously, we cannot observe the actual job hiring process. Being employed by the firm that had already employed a past collaborator does not necessarily imply that the collaborator provided a job reference on the person to the firm. Therefore, our assumption that an inventor and a firm exchange job match information through the past collaborator (or collaborators) should be challenged carefully. Yet, unfortunately, we cannot provide any empirical support for that assumption using the data at our disposal. Second, alternative mechanisms might well explain differences in job tenure length and patent productivity between networked and non-networked inventors. For example, if networked inventors, after their job change, learn job skills in an employment relationship with previous collaborators more easily and readily than non-networked inventors, the former become more skillful, and thus less vulnerable to job termination and more productive in patent applications than the latter. Such "ex post learning" theory might explain the nonuniformity in the productivity gap observed in the regression results. It would be consistent with the idea that non-networked inventors take some time to learn how to interact with other researchers, so that, after years of development, they eventually "catch up" to networked inventors. ${ }^{26}$ We are thus obliged to acknowledge that the "ex ante learning" story that we have proposed so far is not the only theory that is consistent with the empirical findings.

Despite all of these qualifications, we hope that our analysis sheds light on, as a minimum, one important aspect of the job search and matching process that inventors and firms face. Of course, examining the alternative theories about learning, which are the "ex ante learning" theory and the "ex post learning" theory, is no doubt an important research goal, but it requires more detailed information about the job hiring process, which, unfortunately, is not available from our patent-based data set. Therefore, we leave a complete analysis of this issue for future research.

The results of this paper have several implications for future research. First, it is possible to extend our model to incorporate the two learning processes, "ex ante learning" and "ex post learning", to explain the job search and matching between inventors and firms. One such attempt was made by Nagypal (2007), although she does not explicitly take into account learning through networks. With the wider availability of job hiring data, an empirical model could be estimated.

Second, although it is suggested that network-based recruitment enables firms to hire better-matched inventors than other recruitment methods, it is found that many inventors were not necessarily recruited through network references. This may raise the possibility that firms self-select themselves into segregated labor markets in which some firms use network-based recruitment methods and other firms use non-networkbased methods such as public recruitment. This paper assumes that a firm's choice of recruitment method is exogenously given by some process unrelated to job search and matching, and thus does not explicitly account for a firm's endogenous use of networks in hiring inventors. Therefore, future work is needed to address this issue.

Third, as mentioned in the introduction, our model is based on "one-sided" search behaviors of inventors with the assumption of firms' behaviors being perfectly competitive. The results must be viewed within this partial equilibrium context. Hence, in future research our search model should be extended to a general equilibrium frame-

${ }^{26}$ We thank an anonymous referee for pointing out this possibility. 
work that explicitly describes how inventors and firms get together and how the match surplus is distributed among agents. In such an equilibrium model, wages should be determined by the flow of contacts between inventors and firms and the degree of search and matching frictions in the labor market. Various approaches have been proposed in previous studies to model the endogenous wage determination process. A "postingwage equilibrium" approach, taken by Postel-Vinay and Robin (2002) seems promising, in which the inventor's bargaining power is essentially zero, but the wage is set to the maximum possible productivity of the inventor due to competitive pressures among firms. It can be shown that, under certain assumptions, the equilibrium accepted wage distribution is fully determined by the search friction and the productivities of inventors and firms. Their multi-step estimation method that separates the parameters that can be estimated from a cross-sectional wages from the parameters requiring transition data for identification may allow us to identify and estimate the structural parameters of the equilibrium search model, if a rich matched employer-employee panel data on inventors' productivities, job flows and wages becomes available.

Finally, our findings indicated that firms may use interfirm R\&D networks not only as a way of exploiting external knowledge, as previously reported by the industrial organization literature (e.g., Singh, 2005), but also as a way of recruiting inventors with good match values and high research abilities through inventors' referrals. This unique role of R\&D networks, which was downplayed by previous studies, may explain the observed relationship between firms' inventive productivity and their network position in R\&D networks (Ahuja, 2000; Schilling and Phelps, 2007). The empirical finding of this paper suggested that firms with higher connectivity in R\&D networks can recruit better-matched inventors than those with low connectivity because the former firms can use more interfirm referrals than the latter firms in their hiring processes. Thus, a future extension of this paper will examine this hypothesis, and it will be a step forward in understanding the mechanism of how the global $R \& D$ network structure influences firm-level innovation. 


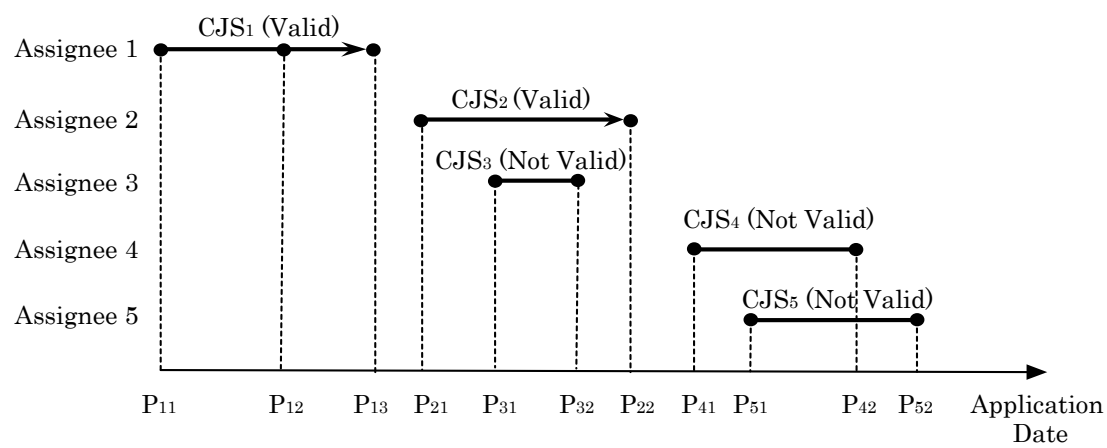

Figure 1: An example of employment history construction. The inventor has applied for patents from five different assignees, thus has five candidate job spells (CJSs). $C J S_{3}$ is not a valid job spelll because it is contained in $C J S_{2}$. CJ $S_{4}$ and $C J S_{5}$ are not job spells because they overlap with each other.

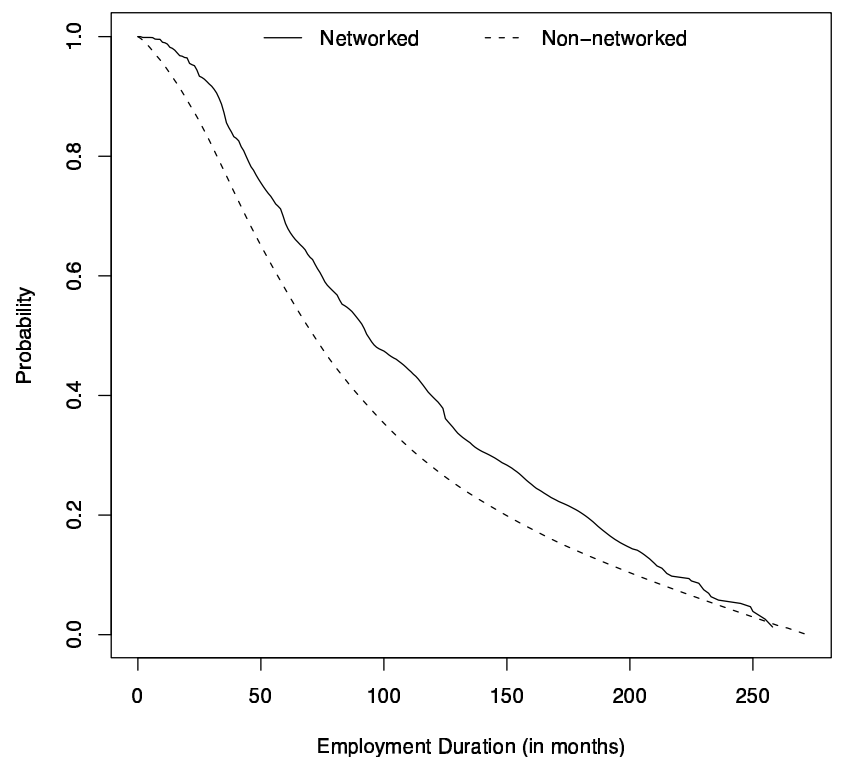

Figure 2: Survival Curves for Employment Duration after Job Transition 

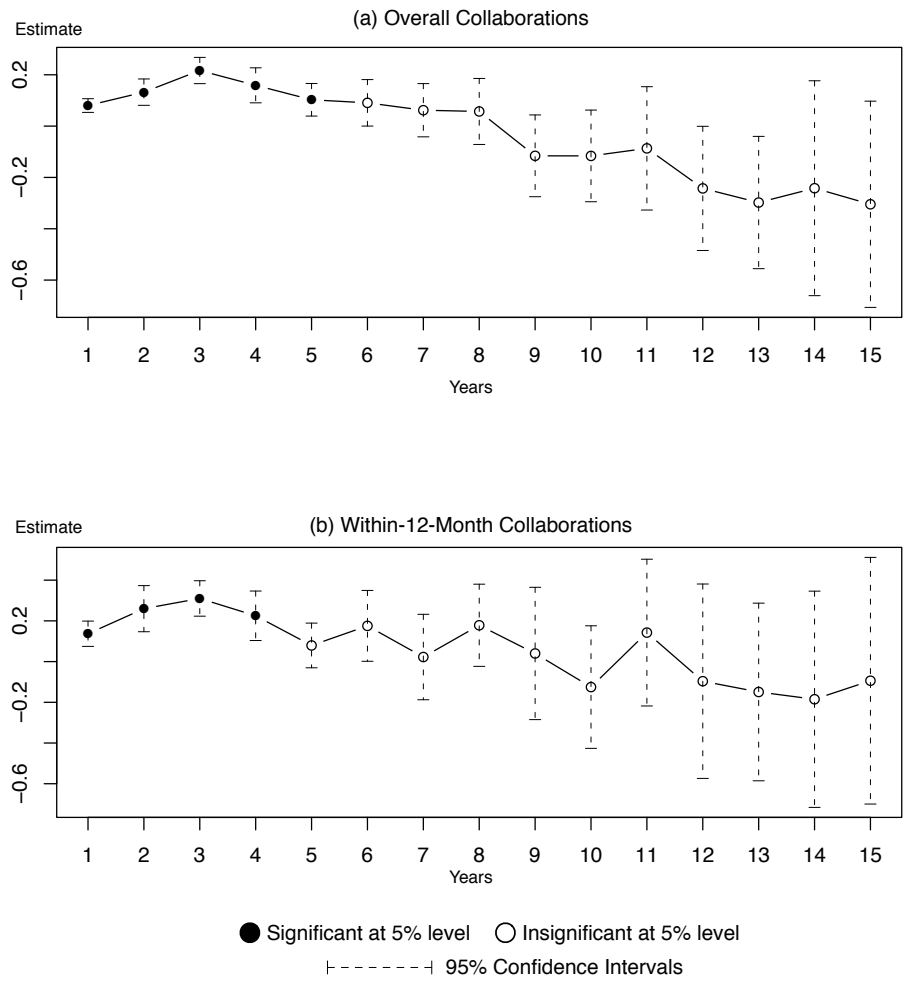

Figure 3: Estimation result of the productivity premium $\rho_{k}$ of networked inventor over non-networked inventor in tenure year $k$. The estimates are based on the productivity growth regression model (11). Network dummies are constructed from the overall collaborations (a) and within-12 month collaborations (b). 

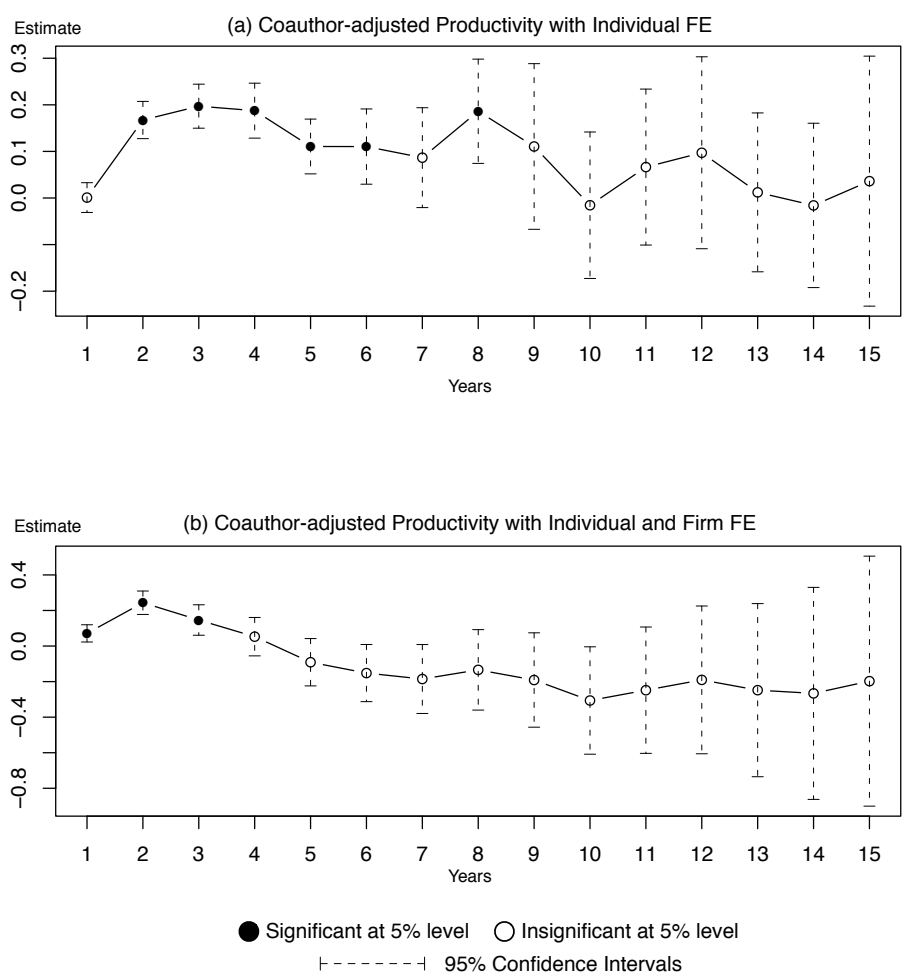

Figure 4: Estimation result of the productivity premium $\rho_{k}$ of networked inventor over non-networked inventor in tenure year $k$. The estimates are based on the productivity growth regression model (11) of coauthor-adjusted productivity. Within-12-month collaborations are considered for the estimation. 
Table 1: Summary Statistics: Inventors and Jobspells

\begin{tabular}{lrr}
\hline & Count & Fraction \\
\hline All Inventors & 271,348 & 1 \\
Job hopped Inventors & 51,896 & 0.19 \\
& & \\
All Candidate Job Spells & 120,862 & 1 \\
Overlapped Spells & 5,555 & 0.05 \\
& & \\
Job Spells & 115,307 & 1 \\
Networked Inventors & 10,758 & 0.09 \\
$\quad$ within 36 months & 6,704 & 0.06 \\
$\quad$ within 24 months & 5,081 & 0.04 \\
$\quad$ within 12 months & 2,538 & 0.02 \\
Non-networked Inventors & 104,549 & 0.91 \\
\hline
\end{tabular}

Table 2: Employment Duration and Patent Productivity

\begin{tabular}{lccc}
\hline & Mean & S.D. & Median \\
\hline EMPLOYMENT DURATION & & & \\
All Inventors & 95.320 & 87.286 & 75 \\
Networked Inventors & 109.371 & 67.855 & 93 \\
Non-networked Inventors & 90.566 & 90.027 & \\
\hline PATENT PRODUCTIVITY & & & \\
All Inventors & 1.121 & 0.615 & 1 \\
Networked Inventors & 1.126 & 0.820 & 1 \\
Non-networked Inventors & 0.989 & 0.588 & 1 \\
\hline
\end{tabular}


Table 3: Weibull Hazard Regression Results

\begin{tabular}{|c|c|c|c|c|c|}
\hline & \multicolumn{2}{|c|}{$\begin{array}{c}\text { OVERALL } \\
\text { COLLBORATION }\end{array}$} & \multicolumn{3}{|c|}{$\begin{array}{l}\text { LIMITED INTERVAL } \\
\text { COLLABORATION }^{\dagger}\end{array}$} \\
\hline & (1) & (2) & $\begin{array}{l}\text { WITHIN } 36 \\
\text { (3) }\end{array}$ & $\begin{array}{l}\text { WITHIN } 24 \\
\text { (4) }\end{array}$ & $\begin{array}{l}\text { WITHIN } 12 \\
(5)\end{array}$ \\
\hline Network referral dummy: $\delta$ & $\begin{array}{c}-.5058 \\
(.031)\end{array}$ & $\begin{array}{c}-.4675 \\
(.030)\end{array}$ & $\begin{array}{c}-.4325 \\
(.039)\end{array}$ & $\begin{array}{c}-.4269 \\
(.044)\end{array}$ & $\begin{array}{c}-.4395 \\
(.060)\end{array}$ \\
\hline Research field dummies: & & & & & \\
\hline Chemical & $\begin{array}{r}-1.2045 \\
(.031)\end{array}$ & $\begin{array}{r}-1.1882 \\
(.031)\end{array}$ & $\begin{array}{r}-1.2110 \\
(.031)\end{array}$ & $\begin{array}{r}-1.2136 \\
(.031)\end{array}$ & $\begin{array}{r}-1.2171 \\
(.031)\end{array}$ \\
\hline Comp.\& Comm. & $\begin{array}{r}-1.0751 \\
(.035)\end{array}$ & $\begin{array}{r}-1.0771 \\
(.035)\end{array}$ & $\begin{array}{r}-1.0783 \\
(.035)\end{array}$ & $\begin{array}{r}-1.0782 \\
(.035)\end{array}$ & $\begin{array}{r}-1.0783 \\
(.035)\end{array}$ \\
\hline Drugs \& Medical & $\begin{array}{r}-1.0293 \\
(.039)\end{array}$ & $\begin{array}{r}-1.0223 \\
(.039)\end{array}$ & $\begin{array}{r}-1.0362 \\
(.038)\end{array}$ & $\begin{array}{r}-1.0367 \\
(.038)\end{array}$ & $\begin{array}{r}-1.0387 \\
(.038)\end{array}$ \\
\hline Elec. \& Electronics & $\begin{array}{r}-1.1066 \\
(.031)\end{array}$ & $\begin{array}{r}-1.1008 \\
(.031)\end{array}$ & $\begin{array}{r}-1.1000 \\
(.031)\end{array}$ & $\begin{array}{c}-1.1003 \\
(.031)\end{array}$ & $\begin{array}{r}-1.0996 \\
(.031)\end{array}$ \\
\hline Mechanical & $\begin{array}{r}-1.1505 \\
(.030)\end{array}$ & $\begin{array}{r}-1.1476 \\
(.030)\end{array}$ & $\begin{array}{r}-1.1476 \\
(.030)\end{array}$ & $\begin{array}{r}-1.1490 \\
(.030)\end{array}$ & $\begin{array}{r}-1.1489 \\
(.030)\end{array}$ \\
\hline Others & $\begin{array}{r}-1.0775 \\
(.031)\end{array}$ & $\begin{array}{r}-1.0782 \\
(.030)\end{array}$ & $\begin{array}{r}-1.0763 \\
(.030)\end{array}$ & $\begin{array}{r}-1.0769 \\
(.030)\end{array}$ & $\begin{array}{r}-1.0748 \\
(.030)\end{array}$ \\
\hline Total past productivity & $\begin{array}{l}.0287 \\
(.002)\end{array}$ & & $\begin{array}{l}.0273 \\
(.002)\end{array}$ & $\begin{array}{l}.0269 \\
(.002)\end{array}$ & $\begin{array}{l}.0259 \\
(.002)\end{array}$ \\
\hline Average past productivity & & $\begin{array}{l}.0326 \\
(.004)\end{array}$ & & & \\
\hline Total research experience & $\begin{array}{r}-.0893 \\
(.009)\end{array}$ & $\begin{array}{c}-.0819 \\
(.009)\end{array}$ & $\begin{array}{c}-.0965 \\
(.009)\end{array}$ & $\begin{array}{c}-.0958 \\
(.009)\end{array}$ & $\begin{array}{r}-.0900 \\
(.009)\end{array}$ \\
\hline$(\text { Total research experience })^{2}$ & $\begin{array}{l}.0036 \\
(.000)\end{array}$ & $\begin{array}{l}.0035 \\
(.000)\end{array}$ & $\begin{array}{l}.0039 \\
(.000)\end{array}$ & $\begin{array}{l}.0039 \\
(.000)\end{array}$ & $\begin{array}{l}.0037 \\
(.000)\end{array}$ \\
\hline $\log \alpha^{\ddagger}$ & $\begin{array}{l}.4142 \\
(.010)\end{array}$ & $\begin{array}{l}.4125 \\
(.010)\end{array}$ & $\begin{array}{l}.4183 \\
(.010)\end{array}$ & $\begin{array}{l}.4200 \\
(.010)\end{array}$ & $\begin{array}{l}.4231 \\
(.010)\end{array}$ \\
\hline Constant & $\begin{array}{r}-5.0659 \\
(.074)\end{array}$ & $\begin{array}{r}-5.0755 \\
(.074)\end{array}$ & $\begin{array}{r}-5.1001 \\
(.075)\end{array}$ & $\begin{array}{c}-5.1243 \\
(.074)\end{array}$ & $\begin{array}{r}-5.1809 \\
(.074)\end{array}$ \\
\hline Log-likelihood & -16489 & -16510 & -16573 & -16592 & -16619 \\
\hline Observations & 33178 & 33178 & 33178 & 33178 & 33178 \\
\hline
\end{tabular}

NOTE.- Dependent variable is inventor's employment duration. Robust standard errors are in parentheses. All variables are statistically significant at less than one percent level $(p<.01)$.

$\dagger$ Collaborations from limited intervals before the job switch are considered. The Intervals are within 36 months, 24 months, and 12 months before the job switch.

$\ddagger$ The duration dependence is represented by parameter $\alpha$. 
Table 4: Fixed-effect Poisson Regression Estimates

\begin{tabular}{|c|c|c|c|c|}
\hline & $\begin{array}{l}\text { Overall } \\
(1)\end{array}$ & $\begin{array}{l}\text { Within } 36 \\
(2)\end{array}$ & $\begin{array}{l}\text { Within } 24 \\
(3)\end{array}$ & $\begin{array}{l}\text { Within } 12 \\
(4)\end{array}$ \\
\hline Network referral dummy: $\rho$ & $\begin{array}{l}0.1023 * * * \\
(0.0169)\end{array}$ & $\begin{array}{l}0.1270 * * * \\
(0.0165)\end{array}$ & $\begin{array}{l}0.1551 * * * \\
(0.0232)\end{array}$ & $\begin{array}{l}0.1806 * * * \\
(0.0330)\end{array}$ \\
\hline Referee's productivity & $\begin{array}{l}0.0012 * \\
(0.0006)\end{array}$ & $\begin{array}{l}0.0014 * * * \\
(0.0005)\end{array}$ & $\begin{array}{l}0.0014 * * \\
(0.0006)\end{array}$ & $\begin{array}{l}0.0017 * * * \\
(0.0006)\end{array}$ \\
\hline Past total productivity & $\begin{array}{l}0.0394 * * * \\
(0.0029)\end{array}$ & $\begin{array}{l}0.0395 * * * \\
(0.0025)\end{array}$ & $\begin{array}{l}0.0395 * * * \\
(0.0025)\end{array}$ & $\begin{array}{l}0.0392 * * * \\
(0.0026)\end{array}$ \\
\hline Firm's productivity & $\begin{array}{l}0.3045 * * * \\
(0.0867)\end{array}$ & $\begin{array}{l}0.3061 * * * \\
(0.0689)\end{array}$ & $\begin{array}{l}0.3072 * * \\
(0.1406)\end{array}$ & $\begin{array}{l}0.3074 * * * \\
(0.1141)\end{array}$ \\
\hline Total research experience & $\begin{array}{l}0.0263 \\
(0.0185)\end{array}$ & $\begin{array}{l}0.0267 \\
(0.0217)\end{array}$ & $\begin{array}{l}0.0270 \\
(0.0216)\end{array}$ & $\begin{array}{l}0.0273 \\
(0.0200)\end{array}$ \\
\hline$(\text { Total research experience })^{2}$ & $\begin{array}{l}0.0011 * * * \\
(0.0001)\end{array}$ & $\begin{array}{l}0.0010 * * * \\
(0.0002)\end{array}$ & $\begin{array}{l}0.0010 * * * \\
(0.0002)\end{array}$ & $\begin{array}{l}0.0010 * * * \\
(0.0001)\end{array}$ \\
\hline Within-firm research experience & $\begin{array}{l}0.0062 \\
(0.0050)\end{array}$ & $\begin{array}{l}0.0053 \\
(0.0051)\end{array}$ & $\begin{array}{l}0.0052 \\
(0.0057)\end{array}$ & $\begin{array}{l}0.0048 \\
(0.0060)\end{array}$ \\
\hline$(\text { Within-firm research experience })^{2}$ & $\begin{array}{l}0.0007 * \\
(0.0004)\end{array}$ & $\begin{array}{l}0.0007 * \\
(0.0004)\end{array}$ & $\begin{array}{l}-0.0007 \\
(0.0005)\end{array}$ & $\begin{array}{l}-0.0006 \\
(0.0004)\end{array}$ \\
\hline $\begin{array}{l}\text { Log-likelihood } \\
\text { Observations }\end{array}$ & $\begin{array}{l}-236433.22 \\
286,954\end{array}$ & $\begin{array}{l}-236423.18 \\
286,954\end{array}$ & $\begin{array}{l}-236410.06 \\
286,954\end{array}$ & $\begin{array}{l}-236425.31 \\
286,954\end{array}$ \\
\hline $\begin{array}{l}\text { NoTE.- Dependent variable is the } \mathrm{n} \\
\text { limited intervals before the job swit } \\
\text { months, and } 12 \text { months before the ju }\end{array}$ & ber of patent & pplied by i1 & ntor. Collabo & $\begin{array}{l}\text { ions from } \\
\text { lonths, } 24 \\
\text { rentheses. }\end{array}$ \\
\hline
\end{tabular}

Table 5: Fixed-effect Poisson Regression Using Coauthorship-Adjusted Productivity

\begin{tabular}{cllll}
\hline \hline & Overall & Within 36 & Within 24 & Within 12 \\
\hline PANEL A: INDIVIDUAL FE & & & & \\
Network referral dummy: $\rho$ & $0.0586^{* * *}$ & $0.0564 * * *$ & $0.0732^{* * *}$ & $0.0937^{* * *}$ \\
& $(0.0113)$ & $(0.0124)$ & $(0.0141)$ & $(0.0162)$ \\
Referee's productivity & $0.0010^{* *}$ & $0.0013 * * *$ & $0.0013 * * *$ & $0.0014 * * *$ \\
& $(0.0004)$ & $(0.0004)$ & $(0.0004)$ & $(0.0005)$ \\
\hline PANEL B: INDIVIDUAL AND FIRM FES & & & & \\
Network referral dummy: $\rho$ & $0.0604 * * *$ & $0.0519 * * *$ & $0.0502 * * *$ & $0.0489 * *$ \\
& $(0.0127)$ & $(0.0123)$ & $(0.0152)$ & $(0.0200)$ \\
Referee's productivity & $0.0008 * * *$ & $0.0012 * * *$ & $0.0012 * * *$ & $0.0014 * * *$ \\
& $(0.0003)$ & $(0.0003)$ & $(0.0003)$ & $(0.0003)$ \\
\hline
\end{tabular}

NOTE.- Dependent variable is the coauthorship-adjusted productivity of inventor. Collaborations from limited intervals before the job switch are considered. The Intervals are within 36 months, 24 months, and 12 months before the job switch. Robust standard errors are in parentheses. $* p<.1$. $* * p<.05 . * * * p<.01$. 


\section{Appendix}

\section{Definitions of the Variables}

$N E T_{i f}$ : a dummy variable that takes one if an inventor $i$ refers his collaboration network in the job turnover to firm $f$ and takes zero otherwise.

Tenure $_{i f t k}(k=1, \ldots, 22)$ : the $k$ th tenure year dummy for inventor $i$ at firm $f$. It takes one if inventor $i$ is employed in $k$-th year by firm $f$ and takes zero otherwise.

Research field dummies : Six dummy variables according to the following six industrial categories:

Chemical : chemical.

Comp.\& Comm. : computer and communications.

Drugs \& Medical : drugs and medical.

Elec. \& Electronics : electrical and electronics.

Mechanical : mechanical.

Others : other research fields, such as agriculture, amusement devices, apparel and textile, etc.

See the detailed definition of each catagory in http://www.nber.org/ patents/subcategories.txt.

Total research experience : Elapsed years for an inventor since his/her first patent application.

Within-firm research experience : Elapsed years for an inventor since his/her first patent application in the tenure.

Total past productivity : Cumulative number of patents applied by an inventor up to a given year.

Average past productivity : Annual average of the number of patent applications of an inventor up to a given year.

Firm's productivity : The number of patents applied by inventors in an assignee in one year.

Referee's productivity : The number of patents applied by the referee of an inventor in one year.

The first-year dummy : The dummy variable indicating the first year of patent application period in the tenure.

Annual dummies Dnn $(n n=75, \ldots, 97)$ : Yearly dummies defined over 1975-1997. 


\section{References}

Agrawal, A., I. Covkburn, And J. McHale (2006): “Gone but not Forgotten: Knowledge Flows, Labor Mobility, and Enduring Social Relationships,” Journal of Economic Geography, 6(5), 571-591.

AhujA, G. (2000): “Collaboration Networks, Structural Holes, and Innovation: A Longitudinal Study,” Administrative Science Quarterly, 45(September), 425-455.

Almeida, P., And B. Kogut (1999): "Localization of Knowledge and the Mobility of Engineers in Regional Networks," Management Science, 45(7), 905-917.

Antoninis, M. (2006): "The Wage Effects from the Use of Personal Contacts as Hiring Channels," Journal of Economic Behavior and Organization, 59(1), 133-146.

ARrow, K. J. (1962): "Economic Welfare and the Allocation of Resources for Invention," in The Rate and Direction of Inventive Activity: Economic and Social Factors, ed. by R. R. Nelson, vol. 13 of NBER Special Conference Series, pp. 609625. Princeton University Press, New Jersey.

BRIDGES, W., AND W. VillemeZ (1986): "Informal Hiring and Income in the Labor Market,” American Sociological Review, 51(4), 574-582.

Burdett, K., And D. T. Mortensen (1998): “Wage Differentials, Employer Size, and Unemployment," International Economic Review, 39(2), 257-273.

Calvo-Armengol, A., And M. O. Jackson (2004): "The Effects of Social Networks on Employment and Inequality," American Economic Review, 94(3), 426454.

Casella, A., and N. Hanaki (2006): "Why Personal Ties Cannot Be Bought," American Economic Review, Papers and Proceedings, 96(2), 261-264.

(2008): "Information Channels in Labor Markets. On the Resilience of Referral Hiring," Journal of Economic Behavior and Organization, 66(3-4), 492-513.

ECKSTEIn, Z., AND G. J. VAN DEN BERG (2007): "Empirical Labor Search: A Survey," Journal of Econometrics, 136(2), 531-564.

Granovetter, M. (1995): Getting a Job, A Study of Contacts and Careers. 2nd Edition. University of Chicago Press.

Hall, B. H., A. B. JafFe, And M. Trajtenberg (2001): “The NBER Patent Citations Data File: Lessons, Insights and Methodological Tools,” Working Papers 8498, National Bureau of Economic Research.

Hall, B. H., And R. H. Ziedonis (2001): "The Patent Paradox Revisited: An Empirical Study of Patenting in the U.S. Semiconductor Industry, 1979-1995," The RAND Journal of Economics, 32(1), 101-128. 
Hausman, J., B. H. Hall, and Z. Griliches (1984): "Econometric Models for Count Data with an Application to the Patents-R\&D Relationship," Econometrica, 52(4), 909-938.

HoIsL, K. (2007): "Tracing Mobile Inventors - The Causality between Inventor Mobility and Inventor Productivity," Research Policy, 36(5), 619-636.

IOANNIDES, Y. M., AND L. D. LouRY (2004): “Job Information Networks, Neighborhood Effects and Inequality," Journal of Economic Literature, 42(4), 1056-1093.

JovanoviC, B. (1984): "Matching, Turnover, and Unemployment," The Journal of Political Economy, 92(1), 108-122.

Kim, J., AND G. MARSChKe (2005): "Labor Mobility of Scientists, Technological Diffusion, and the Firm's Patenting Decision,” RAND Journal of Economics, 36(2), 298-317.

Kugler, A. D. (2003): "Employee Referrals and Efficiency Wages," Labor Economics, 10(5), 531-556.

Levin, R. C., A. K. Klevorick, R. R. Nelson, S. G. Winter, R. Gilbert, AND Z. GRILICHES (1987): "Appropriating the Returns from Industrial Research and Development," Brookings Papers on Economic Activity, 1987(3), 783-832.

LOURY, L. D. (1983): “The Impact of Informal Networks on Quit Behavior," Review of Economics and Statistics, 65(3), 491-495.

(2006): "Some Contacts are More Equal than Others: Informal Networks, Job Tenure, and Wages," Journal of Labor Economics, 24(2), 299-318.

Marmaros, D., and B. Sacerdote (2002): "Peer and Social Networks in Job Search," European Economic Review, 46(4-5), 870-879.

Marsden, P., And J. Hurlbert (1988): “Social Resources and Mobility Outcomes: A Replication and Extension," Social Forces, 66(4), 1038-1059.

MarX, M., D. Strumsky, and L. Fleming (2007): "Noncompetes and Inventor Mobility: Specialists, Stars, and the Michigan Experiment," HBS Working Paper no. 07-042, Harvard Business School.

Montgomery, J. (1991): "Social Networks and Labor Market Outcomes: Toward an Economic Analysis," American Economic Review, 81(5), 1408-1418.

Mortensen, D. T., And C. A. Pissarides (1999): New Development in Models of Search in the Labor Marketvol. 3, chap. 39, pp. 2567-2627. North Holland.

Mortensen, D. T., And T. Vishwanath (1994): "Personal Contacts and Earnings - It Is Who You Know," Labour Economics, 1(2), 187-201.

NAGypal, E. (2007): “Learning by Doing vs. Learning About Match Quality: Can We Tell Them Apart?," Review of Economic Studies, 74, 537-566. 
PellizZARI, M. (2004): "Do Friends and Relatives Really Help in Getting a Good Job?," CEP Discussion Paper no. 623, Centre for Economic Performance.

Peto, R., And J. Peto (1972): “Asymptotically Efficient Rank Invariant Test Procedures," Journal of Royal Statistical Society. Series A(General), 135(2), 185-198.

PISSARIDES, C. A. (1979): "Job Matching with State Employment Agencies and Random Search,” Economic Journal, 89(3), 818-833.

(2000): Equilibrium Unemployment Theory. The MIT Press, 2nd edn.

Postel-Vinay, F., AND J.-M. RoBIN (2002): "Equilibrium Wage Dispersion with Worker and Employer Heterogeneity," Econometrica, 70(6), 2295-2350.

Rogerson, R., R. SHIMER, AND R. Wright (2005): “Search-Theoretic Models of the Labor Market: A Survey,” Journal of Economic Literature, 43(4), 959-988.

Rosenkopf, L., And P. Almeida (2003): “Overcoming Local Search Through Alliance and Mobility,” Management Science, 49(6), 751-766.

SAlONER, G. (1985): “Old Boy Networks as Screening Mechanisms," Journal of Labor Economics, 3(3), 255-267.

Schankerman, M., R. Shalem, and M. Trajtenberg (2006): "Software Patents, Inventors and Mobility," mimeo.

Schilling, M. A., And C. C. Phelps (2007): "Inter-firm Collaboration Networks: the Impact of Small World Connectivity on Firm Innovation," Management Science, 53(7), 1113-1126.

SimON, C. J., AND J. T. WARnER (1992): "Matchmaker, Matchmaker: The Effect of Old Boy Networks on Job Match Quality, Earnings, and Tenure," Journal of Labor Economics, 10(3), 306-330.

SINGH, J. (2005): "Collaborative Networks as Determinants of Knowledge Diffusion Patterns," Management Science, 51(5), 756-770.

Song, J., P. AlmeidA, And G. Wu (2003): “Learning-by-Hiring: When Is Mobility More Likely to Facilitate Inter-firm Knowledge Transfer?, Management Science, 49(4), 351-365.

TASSiER, T., AND F. MEnCZER (2008): "Social Network Structure, Segregation, and Equality in a Labor Market with Referral Hiring," Journal of Economic Behavior and Organization, 66(3-4), 514-528.

Topel, R. H., And M. P. WARD (1992): "Job Mobility and the Careers of Young Men," The Quarterly Journal of Economics, 107(2), 439-479.

TrajtenberG, M., G. Shiff, and R. Melamed (2006): "The NAMES GAME: Harnessing Inventors' Patent Data For Economic Research,” Working Paper 12479, National Bureau of Economic Research. 
TuRnbull, B. W. (1976): "The empirical Distribution Function with Arbitrarily Grouped, Censored and Truncated Data," Journal of the Royal Statistical Society. Series B (Methodological), 38(3), 290-295.

WoOLDRIDGE, J. M. (2006): "Cluster-sample Methods in Applied Econometrics: An Extended Analysis," mimeo, Department of Economics, Michigan State University. 